\title{
HYPERTROPHIC PYLORIC STENOSIS IN INFANCY TREATED WITH METHYL SCOPOLAMINE NITRATE
}

BY

\author{
BERYL D. CORNER \\ From the Department of Child Health, Bristol University
}

(RECEIVED FOR PUBLICATION FEBRUARY 24, 1955)

The treatment of hypertrophic pyloric stenosis in infancy has provoked many lively discussions and papers during the last 20 years in which the rival claims of medical and surgical treatment have been ably demonstrated. At the same time, increasing interest and skill in diagnosis of the disorders of early infancy have enabled large series of cases to be collected. A review of the literature shows a steadily decreasing mortality rate from this disorder, due not only to improvement in both medical and surgical treatment, but also to the lessened risks of hospital cross infection which have been effected by higher standards of nursing care and hospital accommodation for sick infants.

Still (1924), using medical treatment, reported a mortality of $32.5^{\circ}$ in 234 cases. At the Royal Society of Medicine discussion on this subject in 1941, Paterson quoted six deaths in 95 cases treated by Rammstedt's operation at The Hospital for Sick Children, Great Ormond Street, London, in the year 1939. Levi (1941) treated 100 consecutive breast-fed infants surgically with no mortality. Dobbs (1941) successfully treated 31 cases with methyl atropine nitrate, although in a further 12 infants medical treatment failed, and surgery became necessary; Mackay (1941) also reported a series treated with this drug. The consensus of opinion at that time was in favour of surgical treatment, largely owing to the short period in hospital necessary and the quick cure in experienced hands, medical treatment being mainly advocated for babies in good condition who were more than 8 weeks of age when first diagnosed.

More recently in America, Ladd, Ware and Pickett (1946) reported a $5 \cdot 9^{\circ}$ o mortality rate in 588 surgical cases, and in this country Wood and Smellie (1951) reported 300 cases treated surgically with four deaths. The series of 100 cases, with 11 deaths in 10 years, reported by Ward-McQuaid and Porritt (1950) is a reminder that even with modern skill surgical treatment can carry quite a considerable mortality rate.
In 1951, when this subject was again discussed at the Royal Society of Medicine, Tallerman reported one death in 41 cases treated with methyl atropine nitrate and 26 surgical cases with five deaths, and Denis Browne (1951) reported 407 unselected cases treated surgically with a $2^{\circ}$ o mortality rate in London between the years 1943 and 1945 . Davison (1951) quoted a $3^{\circ}$ o mortality rate in the last 500 cases treated in Newcastle-on-Tyne. Dobbs rightly pointed out that the trend of falling mortality for this disorder corresponded closely with that for the total infant population, suggesting that the same factors might well influence mortality rather than specific improvements in medical and surgical treatment. During this discussion emphasis was properly laid on the importance of early diagnosis, and adequate attention to the minute details of infant care whether medical or surgical treatment was employed.

At Bristol Royal Hospital for Sick Children, in the seven years immediately preceding this investigation, there were 267 cases of pyloric stenosis treated by Rammstedt's operation, 12 of which died, a mortality rate of $4 \cdot 5^{\circ} \mathrm{o}$. In the years $1946-49$ this rate had improved, as in 132 cases there were only three deaths, a mortality rate of $2 \cdot 3^{\circ}{ }_{\mathrm{c}}$.

While surgery seems to have been the treatment of choice in most large centres in Britain, medical treatment has continued to evoke interest. In Scandinavia particularly, fresh encouragement was given by Svensgaard (1935) who first advocated the use of methyl atropine nitrate ('eumydrin'). Jacoby (1946) reported the successful treatment of 50 consecutive cases with this drug and emphasized the part played in medical treatment by a restricted feeding regime. Todd (1947) reported a series of 112 cases treated medically in Leicester, in which 12 deaths occurred. He rightly stressed the factor of locality, and that operation, unless carried out by a skilled surgical and anaesthetic team may give considerably less good results than those reported from the large centres. 
Nyman (1943: 1944) studied the properties of the atropine-scopolamine group of drugs with a view to finding a suitable anticholinergic compound for use in disorders of the alimentary tract. Scopolamine hydrobromide has in many respects the most powerful anticholinergic action of this group of drugs, but its action on intestinal musculature is only about half that of atropine sulphate, and therapeutic use is limited owing to its powerful central inhibiting action. Increased cholinergic activity of atropine by methylation had already been demonstrated, and Nyman (1944) synthesized a new substance by the transformation of the trivalent nitrogen in scopolamine into methylated pentavalent nitrogen (Fig. 1).

The most important property of this new compound is the elimination of central inhibitory action, although big doses have the same central excitatory effect as atropine and methyl atropine. Investigation of the spasmolytic effect on guinea-pig intestine showed that there appeared to be a selectively increased effect on smooth musculature without the appearance of undue side-effects such as dryness and mydriasis, which is the most important advance compared with the atropine derivatives, and tachycardia was not a noticeable problem. Investigation of methyl scopolamine salts showed that the nitrate was the most effective preparation, probably due to a slower rate of elimination.

This experimental work indicated that the spasmolytic effect on guinea-pig intestine of methyl scopolamine nitrate was five times greater than atropine, and two to three times greater than methyl atropine nitrate. A.B. Pharmacia (Stockholm) manufactured this drug under the trade name of
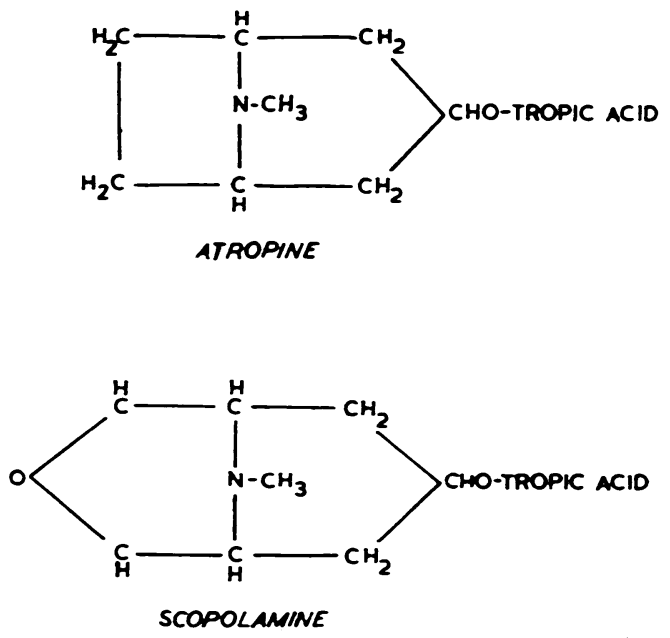

FKG. 1.-Formulae of atropine-scopolamine and methylated compounds (Nyman, 1944). 'skopyl', and it seemed clearly indicated for clinical trial in the treatment of hypertrophic pyloric stenosis of infancy. Elgenmark (1944) first reported the successful treatment of four cases.

Malmberg (1949) reported 136 cases medically treated from 1934 to 1948 . The first 77 infants were treated with atropine derivatives, but $23 \%$ needed surgery as the response was inadequate; one child died from intercurrent infection. From 1945 to 1948, 'skopyl' was used for 59 cases; one died from gastro-enteritis but none required operation.

In view of Malmberg's claim that 'skopyl' is more efficient, quicker and less dangerous than treatment with atropine or 'eumydrin', and that it has greatly reduced the need for surgery, the present investigation was undertaken to evaluate its use in the treatment of infantile hypertrophic pyloric stenosis.

In assessing the claims of any particular line of treatment, certain questions must be answered: (1) In what proportion of cases does the treatment cure or relieve the disease? (2) Has the treatment any risks or mortality of its own? (3) Does it necessitate the exposure of the patient to any other undesirable risks, and, if so, are these adequately compensated for by the safety and efficiency of the treatment?

A follow-up survey of the patients and a radiological study of a limited number of cases was made to show the changes occurring in the pyloric canal during and after treatment. The findings of these will be reported in a subsequent paper.

\section{Clinical Material}

In order that the experimental trial should be carried out on an unselected sample, 117 cases were obtained as follows:

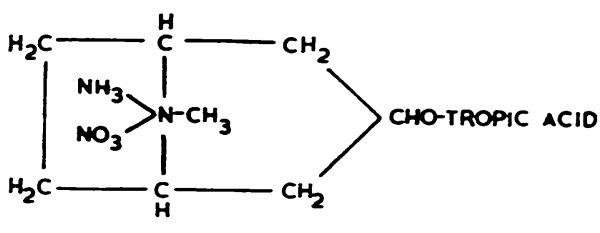

METHYL ATROPINE NITRATE

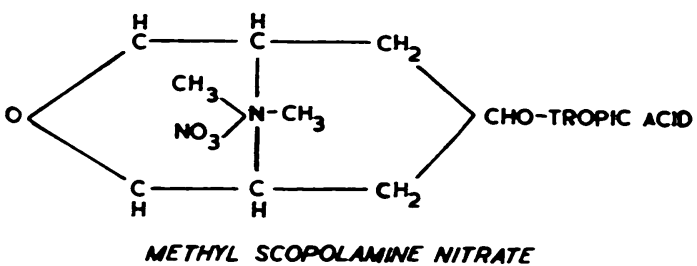

METHYL SCOPOL MINE NITRATE 
(1) From March, 1949 to March, 1950, every case irrefutably diagnosed as pyloric stenosis admitted to the Bristol Royal Hospital for Sick Children and to the paediatric department of Southmead Hospital was included in the trial, with the exception of three consecutive cases in April, 1949 , for which no 'skopyl' was available.

(2) From March, 1950 to September, 1951, all cases were still included at Southmead Hospital. At Bristol Royal Hospital for Sick Children alternate emergency admissions and all cases seen personally by the author before admission were included, other cases being treated surgically. Since September. 1951 , this arrangement also applied to Southmead Hospital.

The criteria for diagnosis were clinical. The two classical physical signs, visible gastric peristalsis and a palpable pyloric tumour were confirmed by at least two experienced observers, and no case was included unless both these signs were present. In cases of doubt, radiology was employed.

\section{Method}

All patients were admitted to hospital, and in order that treatment should not be delayed most of the cases were diagnosed before admission, although sometimes a short period of observation was necessary. During the first two years nearly all babies were nursed in wards reserved for infants or neonatal nurseries. At Bristol Royal Hospital for Sick Children there were 6-ft. high glazed screens between the cots, but no separate cubicles were available.

Cubicled wards became available later in both hospitals, thus enabling better nursing techniques to be instituted, so reducing the risks of crossinfection. Simultaneously a new policy was developed whereby the mothers nursed their own children before discharge from hospital, and care was taken to ensure that no infant returned to a home where acute infection was rife among the household. Limited supplies of 'skopyl' during the first year necessitated strict economy in dosage and the retention of patients in hospital for the whole period of treatment. All these factors contributed considerably to the length of stay in hospital of many patients, and therefore it has not been a primary object of the trial to reduce the length of stay to the minimum period necessary to relieve symptoms.

On admission, information was obtained as to the date of onset and severity of vomiting, as judged by the number of vomits per day and a rough estimate of the size. A clinical estimate of the state of hydration was made and parenteral fluids were given if indicated.
In the early cases in this series an attempt was made to continue a normal feeding regime with 'skopyl', 0.1 mg., administered as a tablet dissolved in half a teaspoonful of water by mouth, 15 minutes before feeds, three times daily. (The 'skopyl' drops advocated by Malmberg were not available until later in the trial.) A few babies rapidly ceased vomiting, but experience showed that for the majority a special feeding schedule of the "ladder" type, as used after Rammstedt's operation, was necessary.

The following is the regime that was eventually adopted:

(1) The stomach is washed out with normal saline.

(2) Five per cent glucose water, or equal parts glucose water and Darrow's solution or saline, is given for the first $\mathbf{2 4}$ hours, at two-hourly intervals, starting with drachms ii and increasing by drachms ii at alternate feeds.

(3) If vomiting has ceased at 24 hours, halfstrength milk feeds are given alternately with the water feeds. When $2 \mathrm{oz}$. is reached, the water feeds are omitted and a three- or four-hourly schedule with night feeds, gradually increasing the size of the feeds until $2 \frac{1}{2} \mathrm{oz}$./lb. daily is taken, calculated on actual body weight.

(4) Human milk or 'frailac' is used for babies who have been breast fed, premature babies, or those in poor condition. For all other babies, half-cream Cow and Gate dried milk was used, as it was thought that the lessened curd formation in the stomach which would result from using a dried milk with reduced protein might be advantageous. Breast feeding is usually resumed on the third or fourth day of treatment, and other milk feeds are brought up to full strength gradually, according to the tolerance of the baby.

(5) Intragastric feeding by milk drip has been employed in a few very ill or feeble babies.

(6) Methyl scopolamine nitrate, $0 \cdot 1 \mathrm{mg}$., is given orally, six times daily 15 minutes before feeds, either as a tablet dissolved in a very small quantity of water, or as drops of alcoholic solution.

(7) If vomiting recurs, the stomach is washed out again, methyl scopolamine nitrate is given by subcutaneous injection, and feeding with watery fluids is started again.

The early cases were retained in hospital until 'skopyl" was discontinued, usually four weeks. Subsequently, cases were treated for a longer period and the dosage was more gradually reduced. As soon as normal feeding was well established, vomiting had entirely ceased, and there was evidence of a steady weight gain, the child was discharged home 


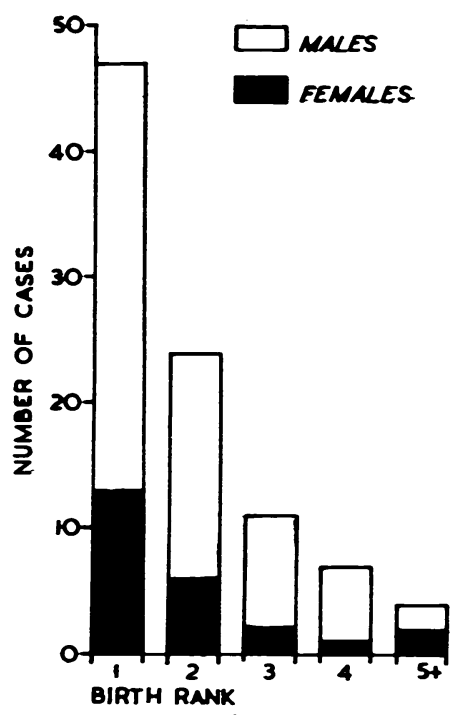

FIG. 2.-Graph showing birth rank. to continue treatment as an outpatient. If still on treatment, the infants were seen weekly for the first four to six weeks after discharge, otherwise fortnightly till 18 weeks of age and subsequent ly monthly.

\section{Results}

One hundred and seventeen babies with hypertrophic pyloric stenosis were treated with methyl scopola mine nitrate ('skopyl'). There was one death, the tenth case in the series, so that 107 consecutive cases have been treated with no mortality. One case, No. 24, was not making satisfactory progress after 19 days of treatment, and Rammstedt's operation was performed with an uneventful recovery.

\section{Analysis of Case Histories}

There were 93 boys and 24 girls, a sex ratio of $3.9: 1$. Fig. 2 shows the place in family of these affected children. One male was the second sibling in his family with this condition, and the maternal uncle of another child had been known to have had Rammstedt's operation for pyloric stenosis in

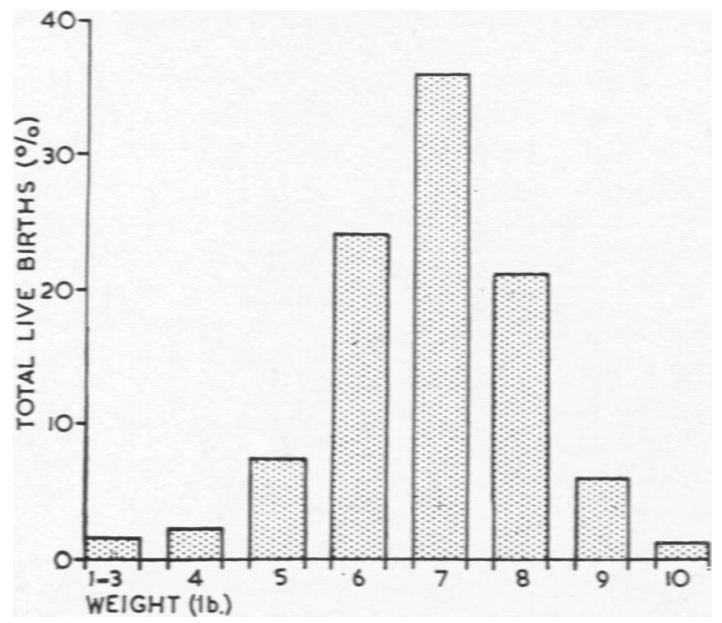

FIG. 3A.-Weight distribution in 6,657 live births in Bristol in 1952. infancy. There was a pair of identical male twins and five other twin infants. The identical twin of one patient was stillborn.

The birth weight distribution of the patients did not differ significantly from that of babies born alive in Bristol during one year of this survey (Fig. 3A and $3 \mathbf{B})$, and included eight premature infants.

Age of Onset. The age at onset of vomiting is shown in Fig. 4. Ten infants vomited in the first week of life sufficiently seriously for medical advice to be sought; three children were seen by the author before the age of 7 days. In none of these cases could a clinical diagnosis of pyloric stenosis be made at that time. Vomiting lessened during the second week, but started again in the third week. Two of these infants continued to vomit intermittently, but were not referred for consultant opinion until the age of 6 weeks when the clinical diagnosis was obvious. Fifty-seven infants vomited before 21 days, and of the whole series, vomiting started in only nine later than seven weeks. One child began to vomit at 82 days, and was admitted to hospital three days later with classical physical signs. The average age of onset of vomiting was 21 days.

The rate of increase of vomiting varied greatly in individual cases. Figs. 4 and 5 show the age at onset of vomiting and the interval that elapsed before treatment was started.

Cases Developing Signs under Observation. Eight children were still in the maternity hospitals when the diagnosis was made. Three were full-term infants who first vomited at 10 to 14 days, and the diagnosis was obvious within three days. The remaining five were premature babies who had been retained in hospital to enable them to reach a

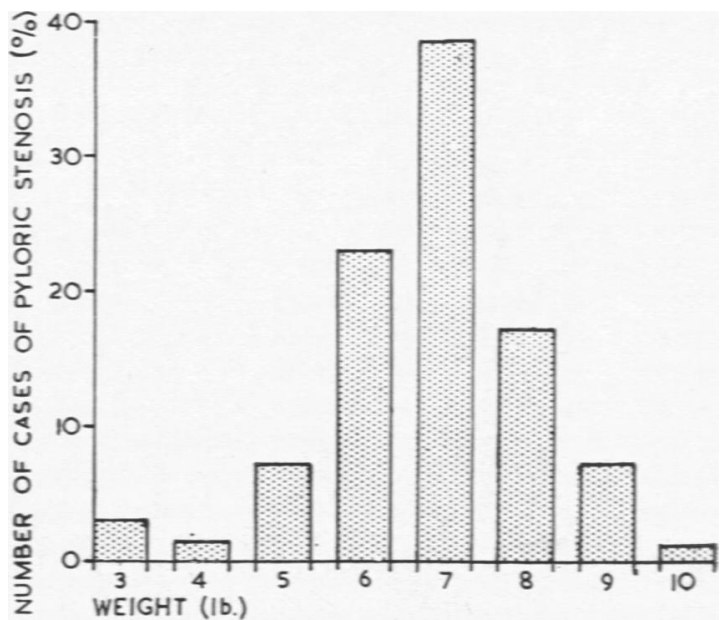

Fig. 3B.-Weight distribution in 117 cases of pyloric stenosis. 


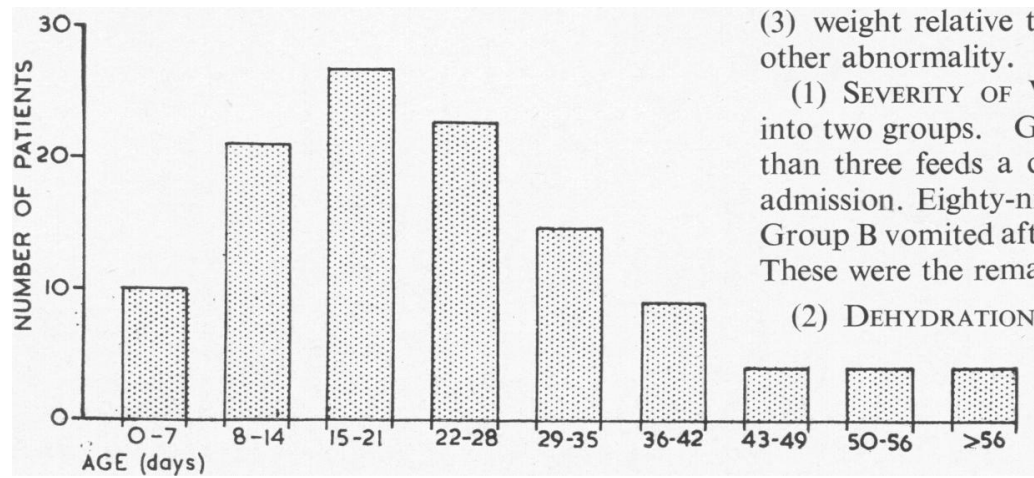

Fig. 4.-Age of onset of vomiting.

satisfactory weight level. The diagnosis was made within 48 hours in three, but the remaining two children vomited less frequently and severely at first, and in one child four weeks elapsed before the pyloric tumour could be definitely palpated. Weight gain stopped abruptly about 48 hours before the diagnosis was confirmed.

The following case history illustrates the occasional difficulty encountered in diagnosis:

B.T., aged 24 days, was a first-born male child (birth weight $7 \mathrm{lb} .4 \mathrm{oz}$.) admitted with a history of vomiting, occasionally projectile, after some feeds for seven days. No clinical signs of pyloric stenosis could definitely be elicited, although he was observed to vomit intermittently. A barium meal showed no delay in emptying the stomach and no obvious narrowing of the pyloric canal. He remained under observation for two weeks, gained weight steadily and was discharged home. At 7 weeks, he was readmitted with severe vomiting for 24 hours.

There were then physical signs and definite radiological evidence of pyloric stenosis, which responded very satisfactorily to treatment.

Condition on Admission. Cases were assessed according to (1) severity of vomiting, (2) dehydration, first few days of treatment. Four children, who relapsed after an initially good response to treatment, received intravenous fluids during treatment of the relapse.

(3) WeIGHT. Cases were divided into five weight groups. Table 1 shows the correlation between the duration of symptoms and weight group on admission.

(4) INFECTION AND Other ABNoRmality. Six children had quite severe infection; oral thrush was present in four patients, one of whom also had purulent conjunctivitis and another had bronchitis. One child was admitted extremely ill with bronchopneumonia; the vomiting was attributed at first to cough, but pyloric stenosis was diagnosed three days after admission. There was one case of purulent rhinitis and conjunctivitis. Two children presented congenital abnormalities: (1) bilateral cleft lip and palate, and (2) mongolism.

Cases of Special Interest. Three cases were included in this series which had received other types of treatment unsuccessfully.

1. M.P., a full-term male infant, developed typical pyloric stenosis at 35 days. Rammstedt's operation was

TABLE 1 CORRELATION BETWEEN DURATION OF SYMPTOMS AND WEIGHT GROUP ON ADMISSION

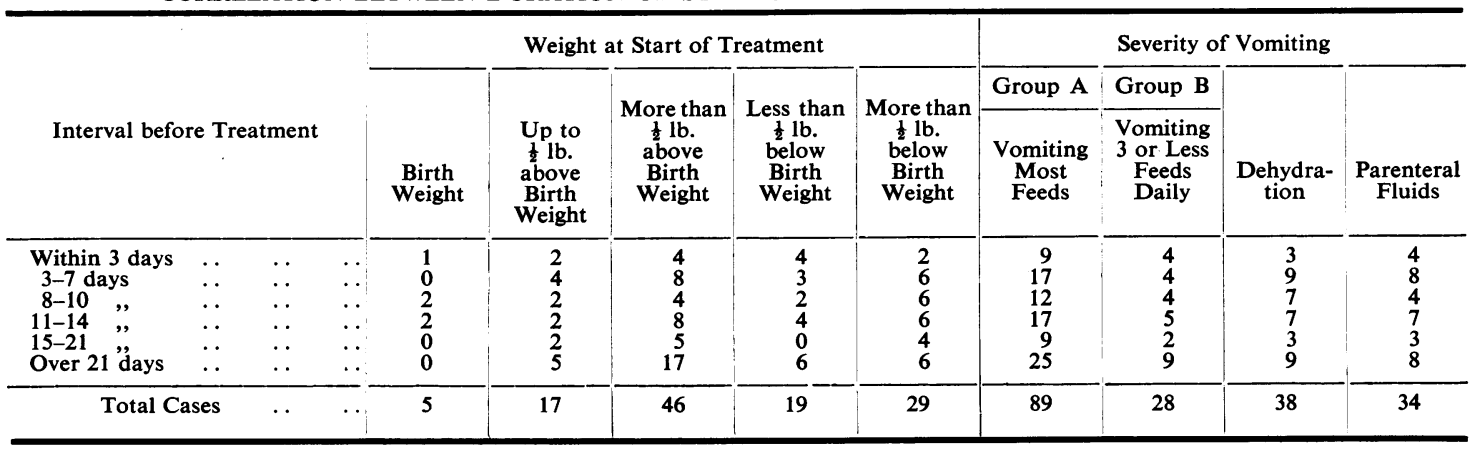




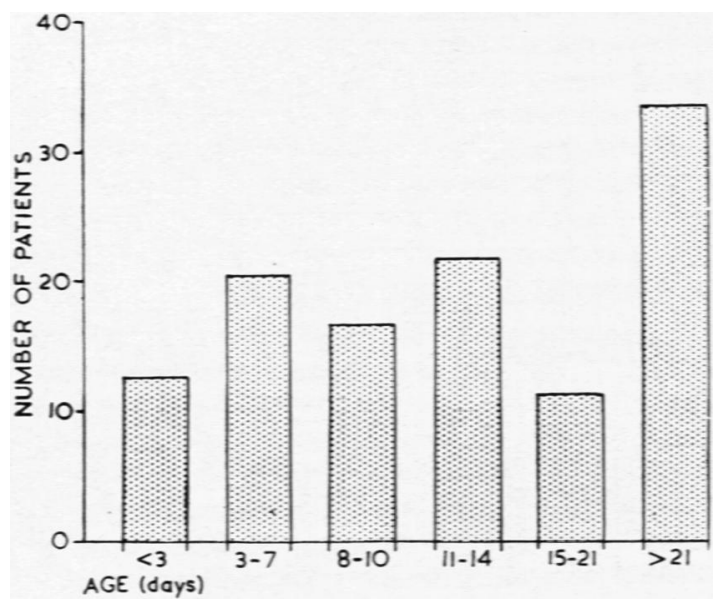

Fig. 5.-Interval before treatment.

performed at a small local hospital outside Bristol. Vomiting continued after operation so that four weeks later he was marasmic. The stomach appeared very large with typical visible peristalis and a very large palpable pyloric tumour. A barium meal confirmed that gastric emptying was greatly delayed and the pyloric canal elongated and threadlike. He responded immediately to treatment with 'skopyl' and made an uninterrupted recovery.

2. V.L. was first seen at 6 months. Birth weight was $8 \mathrm{lb} .12 \mathrm{oz}$. At 6 weeks typical pyloric stenosis had been diagnosed which had been treated with $0.6 \%$ alcoholic solution of 'eumydrin', minims iii, before each feed. This had continued till $4 \frac{1}{2}$ months when the child developed gastro-enteritis and was severely ill. She had made very poor progress and still had frequent projectile vomits. At 6 months, weight was $11 \mathrm{lb} .7 \mathrm{oz}$., typical signs of pyloric stenosis were found, and the diagnosis was confirmed radiologically. She responded rapidly to treatment with 'skopyl'.

3. M.T., a boy, began vomiting in the fifth week and was diagnosed as pyloric stenosis. Treatment with $0.6 \%$ alcoholic solution of methyl atropine nitrate was given for seven days, with marked deterioration in the child's condition and persistent vomiting. The response to 'skopyl' was immediate and he started to gain weight at once.
Feeding. Thirty-nine children were fully breast fed on admission to hospital, and 38 were discharged fully breast fed; one was discharged on some complementary feeding. When breast feeding was resumed it was found necessary to test weigh the babies for a few days as occasionally a very large feed was taken which made the child vomit.

\section{Assessment of the Effects of Treatment}

Cessation of Vomiting. The speed at which vomiting ceased was considered the most important criterion for judging the effect of treatment. In the early cases of the series, the dosage of methyl scopolamine nitrate was undoubtedly inadequate for most children, and it also seemed necessary to put them on a strict feeding regime for the first few days of treatment. Even so, five early cases on a normal food intake and 'skopyl', $0 \cdot 1 \mathrm{mg}$. three times daily, ceased vomiting.

Table 2 shows the rate of cessation of vomiting. It will be noted that 75 infants did not vomit again after treatment was begun (regurgitation of negligible quantities of fluid was ignored), and 19 patients ceased vomiting in 48 hours. Eleven babies vomited intermittently for five days and 12 continued to vomit occasionally after this. These infants usually vomited only once a day or even less frequently, and their condition was such that continuation of treatment seemed justifiable.

During the first year of the trial $55.1 \%$ of 49 patients stopped vomiting, and with greater experience of the method, $77 \cdot 2 \%$ of the remaining 68 patients ceased to vomit as soon as treatment had been started.

Weight Progress. A small loss of weight was usual in the first three days of treatment, but 51 infants started to gain within five days. Forty-four children did not start to gain for five days, and 20 only began to gain weight after 10 days, but owing to intermittent vomiting calorie intakes had been kept low according to their tolerance. All the

TABLE 2

INTERVAL BEFORE START OF TREATMENT AND RATE OF CESSATION OF VOMITING

\begin{tabular}{|c|c|c|c|c|c|c|c|c|}
\hline \multicolumn{4}{|c|}{ Interval } & $\begin{array}{l}\text { No Further } \\
\text { Vomiting }\end{array}$ & $\begin{array}{l}\text { Vomiting } \\
\text { Ceased in } \\
48 \text { Hours }\end{array}$ & $\begin{array}{l}\text { Vomiting } \\
\text { Ceased } \\
48 \text { Hours } \\
\text { to } 5 \text { Days }\end{array}$ & $\begin{array}{c}\text { Continued } \\
\text { after } \\
5 \text { Days }\end{array}$ & Total \\
\hline $\begin{array}{l}\text { Less than } 3 \text { days } \\
3-7 \text { days } \\
8-10 \text {," } \\
11-14 \text { ", } \\
15-21 \text { ",ays } \\
\text { Over } 21 \text { days }\end{array}$ & $\begin{array}{l}\cdots \\
\cdots \\
\cdots \\
\cdots \\
\cdots\end{array}$ & $\begin{array}{l}\cdots \\
\cdots \\
\cdots \\
\cdots \\
\cdots\end{array}$ & $\begin{array}{l}\ldots \\
\cdots \\
\cdots \\
\cdots \\
\cdots\end{array}$ & $\begin{array}{r}7 \\
14 \\
7 \\
16 \\
7 \\
24\end{array}$ & $\begin{array}{l}2 \\
3 \\
1 \\
3 \\
2 \\
8\end{array}$ & $\begin{array}{l}1 \\
3 \\
5 \\
0 \\
1 \\
1\end{array}$ & $\begin{array}{l}3 \\
1 \\
3 \\
3 \\
1 \\
1\end{array}$ & $\begin{array}{l}13 \\
21 \\
16 \\
22 \\
11 \\
34\end{array}$ \\
\hline \multicolumn{2}{|c|}{ Total cases . } & $\cdots$ & $\cdots$ & 75 & 19 & 11 & 12 & 117 \\
\hline
\end{tabular}


successfully treated cases started to gain weight in less than 21 days from the start of treatment.

Length of Stay in Hospital. As has already been stated it was not a primary object of this trial to reduce the length of stay in hospital to the minimum. Twenty-five children were in hospital for less than 14 days; 27 were discharged in 14 to 21 days, 22 at 21 to 28 days, 14 from 28 to 35 days, and 29 after 35 days. Of the 29 long-stay cases, 18 were treated in the first year of the trial and detained in hospital until the end of drug treatment. Eight of these children had relapses during treatment and were started again. In two cases, gastric drip feeding was used with great benefit. Discharge in one child was delayed by an upper respiratory infection and acute otitis media. Five children were detained in hospital owing to social problems or infection in the home. Other treatment was necessary in four cases, for oesophageal hiatus hernia, cleft lip, and two premature babies too small for discharge.

Duration of Administration of the Drug. During 1949 , scarcity of the drug led to early discontinuation in some cases with subsequent relapse. However, treatment for four weeks or less was successful in 10 cases, another three were treated for 28 to 35 days, and four for five to six weeks.

As spontaneous improvement tends to occur in this disorder at about 16 weeks, it was ultimately decided that routine continuation of treatment till about that age would simplify out-patient supervision. The remaining patients were therefore treated for 10 weeks or longer, and the tendency to relapse was eliminated.

Complications. No symptoms or signs attributable to toxic action of the drug were seen, but the oral dosage of $0.6 \mathrm{mg}$. daily was never exceeded, and half this dose by subcutaneous injection was well tolerated. The only complications therefore were relapse of vomiting and intercurrent illness.

Failure to Suppress Vomiting and Rebapses. The only important complication has been inadequate control or relapse of vomiting after cessation for some days. This occurred almost entirely in the first cases treated, and subsequent experience suggests that the dose of 'skopyl' was too small, and insufficient care was taken in regulating the food intake. In more recent cases, if the child was severely dehydrated or much below birth weight, treatment has been begun with subcutaneous injections of methyl scopolamine nitrate, $0.05 \mathrm{mg}$. six times daily.

A recent case of a severely ill baby who was successfully treated demonstrates this point.
J.B. weighed $5 \mathrm{lb}$. on admission at 4 weeks old, having lost $2 \mathrm{lb}$. in weight since birth and with two weeks' history of vomiting. He was dehydrated, very lethargic, with deep jaundice and severe oral thrush. Typical physical signs were present. Subcutaneous fluid was administered to combat dehydration, and 'skopyl' was given by subcutaneous injection of $0.05 \mathrm{mg}$. six times daily. Vomiting ceased completely and an uninterrupted recovery followed. Frailac feeding was used.

Eight cases in the first year relapsed within a week or two of stopping treatment, but were successfully treated again. In the second year, one baby relapsed who had only received treatment for five weeks. With longer periods of treatment no relapses occurred.

Intercurrent Infection. Two children developed upper respiratory infection in hospital, one was complicated by slight secondary diarrhoea and the other by otitis media. One infant, nursed in an 'open' mixed children's ward, developed gastroenteritis which responded fairly rapidly to treatment.

\section{Failures}

The 24th case in this series responded inadequately after prolonged trial and was treated surgically.

M.S., aged 5 weeks, started vomiting at 2 weeks of age. The birth weight was $7 \mathrm{lb}$. $10 \mathrm{oz}$. and admission weight $6 \mathrm{lb} .4 \mathrm{oz}$. Moderate dehydration was corrected with subcutaneous fluid. 'Skopyl' was given by mouth, $0.1 \mathrm{mg}$. three times daily, and subsequently by subcutaneous injection. Vomiting did not cease entirely although it lessened in amount, but, as there was no weight gain, on the 19th day it was decided to perform a Rammstedt's operation, which was followed by uninterrupted recovery.

One patient died, the tenth in the series.

J.L. was a first-born male child (birth weight $9 \mathrm{lb} .1 \mathrm{oz}$.). He was not admitted for 10 days after the onset of vomiting and his weight had by then fallen to $8 \mathrm{lb} .7 \mathrm{oz}$. There was moderate dehydration, severe thrush, purulent conjunctivitis and rhinitis. Treatment was started with 'skopyl', $\mathbf{0 . 1} \mathrm{mg}$. orally three times daily, but this dose was subsequently doubled. Intravenous fluid, $0.43 \%$ dextrose with $0 \cdot 18 \%$ saline, was used to overcome dehydration, and human milk feeds were given.

There was initial improvement, but the striking and unusual feature of the case was severe anorexia, necessitating tube feeding. The oral infection cleared but an upper respiratory infection persisted despite antibiotics, and daily stomach wash-outs yielded large quantities of mucopus. The baby's general appearance remained marasmic. Blood electrolytes on two occasions showed no significant disturbance. The sepsis and poor general condition seemed to contraindicate surgery. After three weeks' treatment, vomiting was controlled but anorexia persisted.

Death occurred unexpectedly after four weeks. Acute dehydration developed in the absence of vomiting or 
TABLE 3

PREMATURE INFANTS (5 LB. 8 OZ. OR LESS AT BIRTH)

\begin{tabular}{|c|c|c|c|c|c|c|c|}
\hline Case No. & Sex & $\begin{array}{c}\text { Birth } \\
\text { Weight }\end{array}$ & $\begin{array}{l}\text { Age at } \\
\text { Onset } \\
\text { (days) }\end{array}$ & $\begin{array}{c}\text { Interval } \\
\text { before } \\
\text { Treatment } \\
\text { (days) }\end{array}$ & $\begin{array}{l}\text { Oz. Relative to } \\
\text { Birth } \\
\text { Weight }\end{array}$ & $\begin{array}{l}\text { Response to } \\
\text { Treatment }\end{array}$ & Remarks \\
\hline $\begin{array}{l}\text { 1. B.H. } \\
\text { 2. J.C. }\end{array}$ & $\begin{array}{l}\mathbf{F} \\
\mathbf{M}\end{array}$ & $\begin{array}{l}3 \cdot 5 \\
3 \cdot 7\end{array}$ & $\begin{array}{l}38 \\
42\end{array}$ & $\begin{array}{l}5 \\
2\end{array}$ & $\begin{array}{l}+26 \\
+16\end{array}$ & $\begin{array}{l}\text { No further vomiting } \\
\text { Vomiting ceased with- } \\
\text { in } 48 \text { hours }\end{array}$ & $\begin{array}{l}\text { Good progress } \\
\text { Treated for retino- } \\
\text { pathy of prematur- }\end{array}$ \\
\hline 3. J.S. & $\mathbf{M}$ & $3 \cdot 10$ & 24 & 2 & +9 & 1 vomit daily for & Good progress \\
\hline $\begin{array}{l}\text { 4. M.P. } \\
\text { 5. J.F. } \\
\text { 6. L.H. } \\
\text { 7. R.M. }\end{array}$ & $\begin{array}{l}\mathbf{M} \\
\mathbf{M} \\
\mathbf{F} \\
\mathbf{M}\end{array}$ & $\begin{array}{l}4 \cdot 1 \\
4 \cdot 11 \\
5 \cdot 1 \\
5 \cdot 4\end{array}$ & $\begin{array}{l}17 \\
50 \\
24 \\
35\end{array}$ & $\begin{array}{r}1 \\
15 \\
28 \\
1\end{array}$ & $\begin{array}{l}+4 \\
+16 \\
+\quad 4 \\
+24\end{array}$ & $\begin{array}{l}\text { No further vomiting } \\
\text { No further vomiting } \\
3 \text { vomits in first } 6 \text { days } \\
\text { No further vomiting }\end{array}$ & $\begin{array}{l}\text { Good progress } \\
\text { Good progress } \\
\text { Good progress } \\
\text { Good progress }\end{array}$ \\
\hline 8. D.T.* & $\mathbf{M}$ & $5 \cdot 7$ & 46 & 11 & +42 & No further vomiting & $\begin{array}{l}\text { Good progress } \\
\text { Uniovular twin }\end{array}$ \\
\hline
\end{tabular}

* J.T. was the uniovular twin of D.T. (birth weight 6 lb. 2 oz.) and also had the disease. Onset at 65 days, treatment started seven days later with good result.

diarrhoea, and plasma electrolytes three hours before death were normal, although the baby appeared to have an acute diuresis. A necropsy showed typical hypertrophic pyloric stenosis; all other organs were normal.

\section{Discussion}

The present series of cases is the largest yet reported of the use of methyl scopolamine nitrate for the treatment of infantile hypertrophic pyloric stenosis. The cases were unselected and included children throughout the normal distribution of birth weights, with all degrees of severity of the disease, some being severely dehydrated. With the exception of two infants, all responded to the treatment, symptoms were relieved and weight gain was satisfactorily re-established.

Lindberg (1946) claimed that since the introduction of this drug the number of cases requiring surgical intervention had been reduced, and the very low toxicity of 'skopyl' was also notable. The present series entirely bears out the Scandinavian experience that most cases of this disease will respond adequately and quickly to treatment, and no toxic symptoms or signs were found in the dosage used. Although the importance of adequate dosage was borne out in the treatment of our early cases, Laursen (1952) reported two deaths in babies attributable to a toxic action of this drug, but his dosage was in excess of that used in this series.

Other accounts of medical treatment using methyl atropine nitrate laid down specific criteria for selecting cases. Jacoby (1946) gave as his indications for surgery in preference to drug treatment the early onset of vomiting and severe dehydration. Todd (1947) suggested as criteria for operation (1) the inefficiency of medical treatment after a trial of seven days, (2) gross dehydration and (3) a birth weight below $6 \frac{1}{2} \mathrm{lb}$.
If these criteria are applied to the present series of patients, it is seen that $65 \%$ began to vomit before the age of 28 days, but the response of these cases was not significantly different from the older children as judged by rate of cessation of vomiting and start of weight gain. The introduction of hyalase has so aided absorption of fluids given subcutaneously that dehydration can now be much more easily controlled with repeated or prolonged subcutaneous infusion, thus obviating the technical problems raised by the necessity for intravenous infusions. In this series, dehydration was not found to be a contraindication to medical treatment, and of 34 children who were considered to need parenteral fluid, only six were given intravenous infusions. (3) Eight babies in this series were premature according to birth weight (see Table 3 ), and the average age of onset of vomiting was $35 \cdot 8$ days. The history of the progress of these children is similar to that noted by Henderson et al. (1952), but in the present very small series the average age of onset was later than in the full-term infants. All these children made a rapid and uneventful response to treatment, and 15 other children with birth weights of $6 \frac{1}{2} \mathrm{lb}$. or less did not present any particular difficulties.

It was thought that length of history might give some indication as to the severity of the disease and likelihood of response to treatment (Fig. 5). It will be seen that in all groups of cases the majority of patients responded quickly to treatment, but of the 50 babies who were treated in less than 10 days from the onset of vomiting, seven (14\%) still had some vomiting after five days of treatment. Five of the remaining 67 infants $(7 \%)$ vomited after five days. This difference is not significant (standard error $=4 \cdot 5$ ). Table 4 gives the details of these 12 patients who, according to Todd's criteria, might 
TABLE 4

INFANTS WHO VOMITED MORE THAN FIVE DAYS

\begin{tabular}{|c|c|c|c|c|c|c|c|}
\hline $\begin{array}{l}\text { Case } \\
\text { No. }\end{array}$ & $\begin{array}{l}\text { Age of } \\
\text { Onset } \\
\text { (days) }\end{array}$ & $\begin{array}{l}\text { Interval } \\
\text { before } \\
\text { Start of } \\
\text { Vomiting } \\
\text { (days) }\end{array}$ & $\begin{array}{c}\text { Birth } \\
\text { Weight } \\
\text { (lb. oz.) }\end{array}$ & $\begin{array}{l}\text { Weight at } \\
\text { Start of } \\
\text { Treatment } \\
\text { (lb. oz.) }\end{array}$ & $\begin{array}{l}\text { Severity of } \\
\text { Vomiting }\end{array}$ & Dehydration & Remarks \\
\hline $\begin{array}{l}\text { 4. J.B. } \\
\text { (Male) }\end{array}$ & 16 & 7 & $6 \cdot 12$ & $5 \cdot 12$ & A. & $\begin{array}{l}\text { Moderate; treated with } \\
\text { subcutaneous fluids }\end{array}$ & $\begin{array}{l}\text { Breast fed. Treated for } \\
49 \text { days. Vomiting } \\
\text { intermittent for } 12 \text { days }\end{array}$ \\
\hline $\begin{array}{l}\text { 7. R.K. } \\
\text { (Male) }\end{array}$ & 33 & 11 & $6 \cdot 7$ & $6 \cdot 14$ & A. & $\begin{array}{l}\text { Severe; intravenous } \\
\text { fluids }\end{array}$ & $\begin{array}{l}\text { Vomited occasionally } \\
\text { for } 13 \text { days. Artificial } \\
\text { feeding. Treated for } \\
47 \text { days }\end{array}$ \\
\hline $\begin{array}{l}\text { 8. M.H. } \\
\text { (Male) }\end{array}$ & 25 & 3 & $7 \cdot 10$ & $7 \cdot 8$ & A. & $\begin{array}{l}\text { Severe; intravenous } \\
\text { fluids }\end{array}$ & $\begin{array}{l}\text { Artificial feeding. In- } \\
\text { termittent vomiting for } \\
8 \text { days. Treated for } \\
49 \text { days. }\end{array}$ \\
\hline $\begin{array}{l}\text { 10. M.L. } \\
\text { (Male) }\end{array}$ & 32 & 10 & $9 \cdot 1$ & $8 \cdot 7$ & A. & $\begin{array}{l}\text { Moderate; intravenous } \\
\text { fluids }\end{array}$ & $\begin{array}{l}\text { Vomited intermittent- } \\
\text { ly for } 21 \text { days. Severe } \\
\text { infection. Died }\end{array}$ \\
\hline 16. S.S. & 28 & 5 & $8 \cdot 1$ & $8 \cdot 13$ & A. & $\begin{array}{l}\text { Became dehydrated on } \\
11 \text { th day; treated with } \\
\text { subcutaneous fluid }\end{array}$ & $\begin{array}{l}\text { Relapse of vomiting on } \\
\text { 10th day. Breast fed. } \\
\text { Treated for } 4 \text { weeks }\end{array}$ \\
\hline $\begin{array}{l}\text { 17. D.W. } \\
\text { (Male) }\end{array}$ & 13 & 3 & $7 \cdot 6$ & $6 \cdot 6$ & A. & $\begin{array}{l}\text { Intravenous fluid on } \\
\text { 19th day }\end{array}$ & $\begin{array}{l}\text { Relapse on } 19 \text { th day. } \\
\text { Treated for } 59 \text { days. } \\
\text { Breast fed }\end{array}$ \\
\hline $\begin{array}{l}\text { 20. J.D. } \\
\text { (Male) }\end{array}$ & 21 & 7 & $7 \cdot 1$ & $7 \cdot 11$ & A. & Moderate & $\begin{array}{l}\text { Vomited for first } 6 \text { days } \\
\text { intermittently. Breast } \\
\text { fed. Treated for } 60 \\
\text { days }\end{array}$ \\
\hline $\begin{array}{l}\text { 24. J.S. } \\
\text { (Female) }\end{array}$ & 14 & 14 & $7 \cdot 10$ & $6 \cdot 4$ & A. & $\begin{array}{l}\text { Severe; intravenous } \\
\text { fluid }\end{array}$ & Operation on 19th day \\
\hline $\begin{array}{l}\text { 39. M.O. } \\
\text { (Male) }\end{array}$ & 28 & 26 & $6 \cdot 4$ & $6 \cdot 13$ & A. & $\begin{array}{l}\text { Moderate; subcutaneous } \\
\text { fluid }\end{array}$ & $\begin{array}{l}\text { Vomited for } 9 \text { days. } \\
\text { Treated for } 70 \text { days. } \\
\text { Breast fed with com- } \\
\text { plement }\end{array}$ \\
\hline $\begin{array}{l}\text { 56. G.W. } \\
\text { (Male) }\end{array}$ & 14 & 14 & $8 \cdot 4$ & $7 \cdot 11$ & A. & $\begin{array}{l}\text { Severe; intravenous } \\
\text { fluid; subcutaneous } \\
\text { 'skopyl' }\end{array}$ & $\begin{array}{l}\text { Occasional vomiting } \\
\text { for } 9 \text { days. } \\
\text { for } 52 \text { days. } \\
\text { fed fully }\end{array}$ \\
\hline $\begin{array}{l}\text { 93. J.M. } \\
\text { (Female) }\end{array}$ & 19 & 3 & $5 \cdot 10$ & $5 \cdot 4$ & B. & Subcutaneous fluid & $\begin{array}{l}\text { Some vomiting for } 10 \\
\text { days }\end{array}$ \\
\hline $\begin{array}{l}\text { 94. M.K. } \\
\text { (Female) }\end{array}$ & 10 & 13 & $6 \cdot 8$ & $6 \cdot 0$ & A. & $\begin{array}{l}\text { Moderate; subcutaneous } \\
\text { fluid }\end{array}$ & $\begin{array}{l}\text { Some vomiting for } 10 \\
\text { days. Also had oeso- } \\
\text { phageal hiatus hernia. } \\
\text { Artificial feeding with } \\
\text { gastric milk drip for } \\
14 \text { days }\end{array}$ \\
\hline
\end{tabular}

all have been submitted to surgery. The only case treated surgically was undoubtedly given too small a dosage of 'skopyl' for some time, and with later experience of the drug would probably have responded adequately. The child who died presents a difficult problem. It has been stated by most authors that infection is a definite indication for medical treatment, but in this infant probably surgery should have been attempted when inadequate response to medical treatment had been clearly demonstrated.

The present series has amply borne out the contention of Jacoby and Todd that a strict feeding regime is necessary.

Does the treatment expose the patient to any other risks? The importance of reducing the length of stay in hospital has always been stressed owing to the risk of cross-infection. In this series, $74 \%$ of infants were in hospital for less than 28 days and $21 \%$ for less than two weeks. With increased experience of the treatment it seems likely that most cases should be capable of discharge home within a fortnight. No attempt was made to treat any patient entirely at home.

The very low rate of intercurrent infection is evidence of the high standard of nursing technique, and the constant vigilance required to prevent contact with infected children. It is noteworthy that the only case of gastro-enteritis occurred in a baby who was nursed in an open ward occupied by children of all ages. It cannot be demonstrated that on the whole in this series admission to hospital had exposed the children to any undue risks.

Todd rightly emphasized the highly important part played by the nursing staff in the treatment of these cases, and the principle should now be accepted that every baby suffering from this disease requires treatment in a properly staffed and equipped paediatric unit. Under such conditions both surgical and medical treatment give very good results with a low mortality rate.

The present trial demonstrated that methyl scopolamine nitrate given either orally or by subcutaneous injection is a safe and highly effective 
drug for medical treatment and can be used efficiently in nearly all cases if supported by a suitable feeding regime and measures to combat dehydration. As no particular factors appeared to influence the response to treatment, Malmberg's suggestion that all cases should be tried on this treatment in the first instance seems to be reasonable.

\section{Summary}

The literature on the medical and surgical treatment of hypertrophic pyloric stenosis of infancy during the last 20 years is reviewed.

Results of treatment of 117 unselected cases with methyl scopolamine nitrate are presented. One child required operation after a trial period of medical treatment. There was one death (a mortality rate of $0 \cdot 8^{\circ}{ }_{0}$ ).

Methyl scopolamine nitrate can be administered by mouth or by subcutaneous injection and no toxic effects were observed in the dosage used.

Response to treatment was usually rapid. Sixtyfour per cent of infants ceased vomiting immediately, and $80^{\circ} \%$ in the first 48 hours.

The factors of birth weight, length of history, or presence of dehydration did not seem to bear any relationship to rapidity of response to treatment. Therefore no particular criteria are suggested as contraindications.

A strict regime of feeding with a reduced fluid intake at the start is essential.

The period in hospital can probably be reduced to less than four weeks and less than 14 days in most cases.
The importance of proper accommodation for nursing these patients in isolation and the necessity for an experienced nursing staff are stressed.

It gives me great pleasure to thank Professor A. V. Neale, at whose instigation this trial was carried out and who allowed many of his patients to be included: also the other physicians and surgeons on the staff of Bristol Royal Hospital for Sick Children for their interest and cooperation, particularly during the first year when all cases were included. Magnificent cooperation was given by the nursing staffs of the two hospitals concerned, but particular mention must be made of Senior Staff Nurse P. Jewell at Bristol Royal Hospital for Sick Children, who nursed many of the babies and helped to work out the feeding regime.

Grateful acknowkdgment is also made for the gift of the original supplies of 'skopyl' by Pharmacia, of Stockholm, and to Dr. Peter Foster for a small supply.

\section{ReFERENCES}

Browne, D. (1951). Proc. roy. Sac. Med., 44, 1057.

Davison, G. (1951). Ibid., 44, 1061.

Dobbs, R. (1941). Ibid., 35, 51.

Elgenmark, O. (1945). Acta paediat., Uppsala, 32, 371.

Henderson, J. L., Brown, J. J. Mason and Taylor, W. C. (1952). Archives of Disease in Childhood, 27, 173.

Jacoby, N. M. (1946). Brit. med. J., 1, 721 .

Ladd, W. E., Ware, P. F. and Pickett, L. K. (1946). J. Amer. med. Ass., 131, 647.

Laursen, E. E (1952). Nord. Med., 48, 1060.

Levi, D. (1941). Proc. roy. Soc. Med., 35, 57.

Lindberg. G. (1946). Nord. Med., 31, 1548.

Mackay, H. M. M. (1941). Archives of Disease in Childhood, 16, 1. Malmberg, N. (1949). Acta paediat., Uppsala, 38, 472.

Nyman, E. (1943). Acta physiol. scand., 6, 256.

(1944). Acta med. scand., 118, 466.

Paterson, D. (1941). Proc. roy. Soc. Med., 35, 49.

Still, G. F. (1924). Common Disorders and Diseases of Childhood, th od. London.

Svensgaard, E (1935). Archives of Disease in Childhood, 10, 443. Todd, R. McLaren (1947). Ibid., 22, 75.

Ward-McQuaid, J. N. and Porritt, B. E. (1950). Lancet, 1, 201.

Wood, E. C. and Smellie, J. M. (1951). Ibid., 2, 3. 